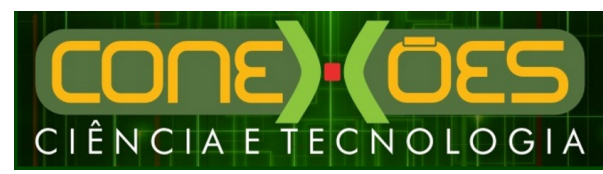

HOTELARIA PARA ANIMAIS DOMÉSTICOS: UM ESTUDO DE CASO SOBRE AS FERRAMENTAS E ESTRATÉGIAS DE MARKETING DE UM HOTEL PET EM FORTALEZA-CEARÁ

\title{
HOTELARIA PARA ANIMAIS DOMÉSTICOS: UM ESTUDO DE CASO SOBRE AS FERRAMENTAS E ESTRATÉGIAS DE MARKETING DE UM HOTEL PET EM FORTALEZA-CEARÁ
}

\author{
Victor Hugo Santos de Castro ${ }^{1}$, Shirley Tainan da Silva Coelho ${ }^{1}$ \\ ${ }^{1}$ Instituto Federal de Educação, Ciência e Tecnologia do Ceará (IFCE) \\ <vsantosdecastro@yahoo.com.br>.<shirleytainnan@hotmail.com>
}

DOI: $10.21439 /$ conexoes.v12i3.1248

\begin{abstract}
Resumo. Este estudo aborda as estratégias e ferramentas de marketing utilizadas na hotelaria para animais domésticos. A pesquisa teve como objetivo geral: analisar as ferramentas de marketing de um hotel pet localizado na cidade de Fortaleza-Ceará, escolhido intencionalmente devido a boa repercussão nas redes sociais. Os objetivos específicos foram: diagnosticar as principais estratégias de marketing para a divulgação e venda dos produtos e serviços do empreendimento; examinar as exigências para a estada do animal; identificar os serviços diferenciais oferecidos pelo hotel pet e sua relação com a fidelização do cliente. Tratou-se de um estudo de caso, de caráter exploratório, com uma abordagem qualitativa. A coleta dos dados foi realizada através de uma entrevista estruturada com um colaborador do hotel pet, em questão. Os dados da pesquisa foram analisados através da transcrição das falas do entrevistado. O estudo aponta que o serviço, o preço e a promoção, são as principais ferramentas de marketing utilizadas pelo empreendimento para a divulgação e venda dos produtos e serviços. A pesquisa aponta ainda que o empreendimento tem se adequado às exigências e tendências do mercado, principalmente no que se refere às tecnologias.
\end{abstract}

Palavras-chaves: Marketing. Estratégias. Hotelaria. Mercado Pet.

\section{ANIMAL HOUSEHOLD HOSPITALITY: A CASE STUDY ON THE TOOLS AND MARKETING STRATEGIES OF A PET HOTEL IN FORTALEZA-CEARÁ}

\begin{abstract}
This study addresses the strategies and marketing tools used in pet food retailing. The research had as general objective: to analyze the marketing tools of a pet hotel located in the city of FortalezaCeará, chosen intentionally due to good repercussion in social networks. The specific objectives were: to diagnose the main marketing strategies for the dissemination and sale of the products and services of the enterprise; examine the requirements for the animal's stay; identify the differential services offered by the pet hotel and its relationship with customer loyalty. It was an exploratory case study with a qualitative approach. The data collection was performed through a structured interview with a collaborator of the pet hotel in question. The data of the research were analyzed through the transcription of the interviewee's speeches. The study points out that service, price and promotion are the main marketing tools used by the enterprise for the dissemination and sale of products and services. The research also points out that the enterprise has been adapted to the demands and tendencies of the market, mainly in what refers to the technologies.
\end{abstract}

Keywords: Marketing. Strategies. Hospitality. Pet Market. 


\section{INTRODUÇÃO}

A hotelaria para animais pode ser entendida como a hospedagem de animais domésticos, em ambiente compatível e exclusivo para este fim, dispondo de facilidades e serviços que ofereçam uma estada afável, aconchegante e segura ao animal, quando distante do seu dono. Os hotéis pet vêm substituindo aos poucos os antigos abrigos para cães e gatos, conhecidos como canis e gatis. Nos hotéis pet, os animais ficam livres, não existem grades ou gaiolas, recebem cuidados quanto à higiene e alimentação de profissionais especializados no período de 24 horas. A palavra inglesa pet significa animal de estimação e é bastante utilizada no segmento veterinário.

Geralmente, tais empreendimentos hospedam cães e gatos e podem fazer algumas exigências para aceitação dos mesmos nas dependências do hotel. A fim de garantir a segurança do animal, a empresa pode solicitar o comprovante de vacina de raiva, gripe e viroses, assim como o preventivo contra carrapatos e pulgas.

Antes da hospedagem, os animais fazem o reconhecimento do local, pois mesmo com todo requinte e conforto, é possível que o animal não se adapte ao lugar. Se o animal apresentar aspectos depressivos, como se recusar a beber água ou se alimentar, os donos devem ser comunicados imediatamente para buscar o pet.

As pessoas que possuem um animal de estimação, por vezes, se deparam com o contratempo de encontrar um local seguro e adequado para deixar seu pet no período das férias, feriados prolongados e viagens. Portanto, o problema deste estudo foi: quais as ferramentas de marketing um hotel pet utiliza para atrair um cliente e fidelizá-lo?

Com o auxílio de recursos tecnológicos, como a internet, é possível visualizar os mais diversos tipos de estabelecimentos do segmento, através de fotos, vídeos e avaliações de pessoas que já utilizaram os serviços daquele local. Muitos clientes utilizam essa ferramenta para fazer comparações entre os diferentes estabelecimentos antes de fazer sua escolha.

Os clientes do segmento pet são muito exigentes, fazendo com que os empresários estejam cada vez mais preocupados e cientes das inovações e informações sobre o mercado, buscando aperfeiçoar o serviço, adotando treinamento à equipe colaboradora como algo indispensável no processo de qualidade.

Atualmente existem inúmeros empreendimentos voltados para a hotelaria de animais domésticos. Sendo assim, este estudo tem como objetivo analisar as ferramentas de marketing de um hotel pet localizado na cidade de Fortaleza - Ceará, escolhido intencionalmente devido a boa repercussão nas redes sociais.
Os objetivos específicos da pesquisa foram: diagnosticar as principais estratégias de marketing para a divulgação e venda dos produtos e serviços do empreendimento; examinar as exigências para a estada do animal; identificar os serviços diferenciais oferecidos pelo hotel pet e sua relação com a fidelização do cliente.

Quanto à metodologia, tratou-se de um estudo de caso, de caráter exploratório, com uma abordagem qualitativa. A coleta dos dados foi realizada através de uma entrevista estruturada com um colaborador do hotel pet, participante desta pesquisa.

Esta pesquisa tem relevância social, pois o segmento pet apresenta-se como um negócio vantajoso e lucrativo, uma vez que impõe relativamente baixo investimento inicial. Ressalta-se ainda que é uma área pouco explorada, portanto, análises e investigações aprofundadas se fazem relevantes para a sociedade em geral, em especial, para professores e estudantes da área de hotelaria, marketing e afins.

Este estudo apresenta seções sobre marketing e estratégias de mercado para conquistar e fidelizar o cliente; as tendências e serviços dos hotéis pet; a metodologia para a obtenção dos dados; a discussão dos resultados obtidos e as considerações sobre a pesquisa.

\section{FUNDAMENTAÇÃO}

\subsection{Marketing - Conceitos, Ferramentas e Fideliza- ção}

Atualmente, as empresas não conseguem se manter no mercado apenas realizando um bom trabalho, devem buscar excelência se quiserem ser bem-sucedidas, uma vez que as mesmas são responsáveis por identificar quem são seus consumidores em potencial, quais as melhores maneiras de suprir suas necessidades, de forma competitiva e lucrativa e o marketing é utilizado como estratégia para a obtenção desses objetivos.

Os seres humanos são indivíduos que possuem aspirações e vontades e o marketing facilita a realização desses anseios. Uma variedade de produtos pode suprir determinada carência, porém a escolha por este ou aquele vai ser determinada pelo entendimento do consumidor com relação aos seus conceitos de valor, experiências anteriores e outros.

A palavra marketing é de origem inglesa e significa mercado. No Brasil passou a ser entendida como mercadologia ou ação no mercado. O marketing dentro da empresa tem como função identificar as necessidades e desejos dos clientes, definir e quantificar a lucratividade, reconhecer os mercados-alvo que se enquadram no atendimento da empresa, estabelecer produtos, serviços e programas ideais para atender os mercados escolhidos e invitar todos os colaboradores da organiza- 
HOTELARIA PARA ANIMAIS DOMÉSTICOS: UM ESTUDO DE CASO SOBRE AS FERRAMENTAS E ESTRATÉGIAS DE MARKETING DE UM HOTEL PET EM FORTALEZA-CEARÁ

ção para refletir nas necessidades do cliente e melhor atendê-lo (KOTLER, 2003).

O marketing pode ser compreendido como o exercício comercial responsável pelo encaminhamento do fluxo de bens e serviços, ao cliente (LAS CASAS 2009). Tais atividades visam benefícios específicos, como fidelização de novos clientes, consumo frequente dos serviços e produtos, dentre outros.

A American Marketing Association (AMA) afirma que o marketing é um método de programação e implementação da criação de um bem e/ou serviço, definição de preço, estratégia de promoção e distribuição dos mesmos (AMA, 1988 apud BOONE; KURTZ, 1998).

O marketing conta com uma combinação de ferramentas que visam criar valores para os consumidores e gerar e manter a competitividade para um produto ou serviço no mercado. Tais ferramentas são denominadas 4P's, representadas por produto, preço, praça e promoção.

Estas ferramentas englobam todos os fatores que influenciam o consumidor, desde a produção até o consumo, potencializando as táticas mercadológicas (KOTLER, 2000). A base de uma empresa é o produto ou serviço que esta oferece, e os negócios devem visar a cada dia suprir as necessidades de seus clientes, para que possa superar a concorrência (KOTLER, 2004).

De acordo com Madruga (2004), o produto deve superar as expectativas dos consumidores, oferecendo vantagens, tais como: comodidade, valor, segurança e confiança. Segundo Kotler (2003), os produtos podem ser ofertados com peculiaridades, que corroboram com a sua atividade básica. Ser pioneiro na introdução de novas características do produto ou serviço é uma das maneiras mais eficazes de competir.

A quantia monetária sobreposta ao produto ou ao serviço chama-se preço. Quanto mais o produto ou serviço satisfizer o consumidor, maior será a disposição deste em pagar determinado valor para obtê-lo. O consumidor faz uma análise entre a vantagem percebida e o seu valor para decidir a importância do produto (SERRENTINO, 2009).

Define-se preço como o capital investido em detrimento das vantagens proporcionadas por um produto e/ou serviço. É uma variável que considera a serventia, as regalias e as qualidades essenciais as quais o cliente é vulnerável (KOTLER, 2000). E trata-se da variável mais flexível do marketing, pois pode ser reduzido ou aumentado rapidamente.

A praça, também chamada de canal de distribuição, é usada para que os produtos e serviços cheguem até o cliente. O relacionamento com esses canais além de gerarem vendas e influenciarem para que o consumidor perceba o produto oferecido, também geram custos devido aos treinamentos de motivação para os prestadores de serviço (KOTLER, 2000).

A promoção dá um incentivo adicional à compra e isso causa um impacto porque leva o consumidor até o produto ou serviço, objetivando a aquisição repentina por impulso. Diante da totalidade de técnicas que as organizações utilizam para que seus serviços e/ou produtos sejam os eleitos pelos consumidores, a promoção é uma excelente estratégia (KOTLER, 2004).

A promoção é a oferta de incentivos instantâneos, de curto prazo como brindes e descontos, com ou sem apoio de propaganda, para estimular a experimentação, aquisição ou repetição de compra de um determinado produto. É uma ferramenta tática de marketing, devendo ser usada por tempo limitado (DIAS 2006). É de suma importância que o marketing, crie métodos criativos de relações públicas e forneça produtos de inigualável qualidade, a fim de garantir a fidelização dos clientes a longo prazo (COBRA, 1992).

Objetivando eficácia máxima no desenvolvimento e aceitação de produtos e serviços junto ao mercado-alvo, é necessário que esses elementos básicos estejam combinados de forma coerente, já que estes influenciam o consumidor no processo de comercialização.

A fidelização é realizada de forma mais efetiva através do marketing de relacionamento. Para fidelizar clientes parte-se do princípio de que é necessário conhecêlo bem, e munidos dessa informação é possível atingir os objetivos empresariais (QUADROS, 2010).

Fidelização de clientes é medir, gerenciar e criar valor. Fidelização é parte integrante da missão da empresa, complementando sistemas de informação, idealizando valores superiores, ou seja, convertendo clientes realizados em clientes leais. Faz-se necessário mensurar a fidelização, assim como também a repercussão dos sistemas de gestão no relacionamento com o consumidor através de pesquisas de satisfação, dentre outros. Fidelização é estreitar o convívio com o cliente, envolvendo-o, instigando-o a usar os produtos e/ou serviços com frequência, retornando sempre ao estabelecimento (SABATINO, 2003).

Pode-se dizer que, um cliente satisfeito acaba fazendo um bom marketing e assim traz novos consumidores. A fidelização de clientes deve ser entendida não somente como uma técnica de marketing, mas também como uma estratégia corporativa (JACON, 2005).

Para que um produto ou serviço atinja um perfil diferenciado no mercado, se faz necessário que, este adquira um padrão de qualidade em que o consumidor fique tão satisfeito que passe a fazer a divulgação do mesmo na sociedade. Sendo assim, se o produto for 
HOTELARIA PARA ANIMAIS DOMÉSTICOS: UM ESTUDO DE CASO SOBRE AS FERRAMENTAS E ESTRATÉGIAS DE MARKETING DE UM HOTEL PET EM FORTALEZA-CEARÁ

bom, terá uma repercussão positiva e caso contrário, terá um efeito negativo.

\subsection{As Tendências do Mercado Pet}

Os animais domésticos merecem um uma atenção especial mercado, pois se apropriaram de uma parcela considerável na vida das pessoas (SMITH, 2004). Sendo assim, os donos de animais de estimação estão a cada dia buscando possibilidades que garantam a qualidade de vida de seus pets, e o mercado vai se adaptando às exigências e oferecendo novas tendências no que tange à oferta de produtos e serviços.

Os serviços que estão se destacando no mercado são: o Happy Day (o pet passará o dia brincando com outros cachorros); academia para cães, caracterizada pela realização de atividades para gastar energia, reduzindo problemas de hiperatividade, agressividade e ansiedade; tratamento terapêutico através de massagens (SEBRAE, 2012).

Estes serviços podem ser encontrados no pet care ou também chamados de pet walk, pet play, pet garden, pet place ou pet space. Trata-se de um empreendimento com espaços reservados exclusivamente ao cuidado e entretenimento do animal de estimação. Oferece áreas para que o dono possa passear, brincar e até mesmo cuidar da higiene do animal, pois alguns possuem sala equipada para banho e tosa (MIRANDA, 2011).

Outras tendências do mercado pet são: atendimento residencial, como banho e tosa; intervenções de saúde modernas, já que a medicina veterinária dispõe de uma gama de equipamentos, medicamentos e tratamentos para zelar a saúde do animal de estimação (SEBRAE 2012).

Serviços gourmet, ofurôs nos centros de estética, roupas de tricot hipoalergênicas feitas à mão, brinquedos educativos importados, joias em ouro, alimentação específica conforme a necessidade de cada raça, esmaltes para unhas, identificação digital e por satélite, refrigerantes, são produtos e serviços que vêm se destacando no mercado pet.

No decorrer dos anos houve um crescimento expressivo no segmento de pet shop com a demanda por alimentos light para cães obesos, alimentos para animais idosos e com problemas cardíacos (BERNASCONI. 2007). Estes serviços podem ser encontrados nos pet shops.

De acordo com o Decreto ${ }^{\circ}$ 40.400/95 do estado de São Paulo Pet Shop é uma loja cujo objetivo é a venda de animais e produtos de uso veterinário e prestação de serviços aos animais de estimação, como tosa e banho (BRASIL, 1995). Ainda de acordo com o decreto os pet shops além de não poderem comercializar medicamen- tos e produtos terapêuticos, devem contar com instalações mínimas necessárias para funcionamento como: superfície impermeável; espaço para tosa, banho, secagem e penteado; espaço para abrigar os animais destinados à venda, separado das demais dependências, dentre outras. Ressaltando que a aplicação de vacinas e exames devem ser realizados no consultório veterinário.

Segundo a Associação Nacional de Fabricantes de Produtos para Animais de Estimação (ANFALPET), o mercado brasileiro de pets foi responsável pela movimentação de 11 bilhões de reais em 2010. Deste total, $66 \%$ se referem à venda de comida para animais de estimação e $20 \%$ a outros serviços prestados pelo setor. O Brasil ocupa a segunda colocação no mercado pet mundial, sendo o primeiro lugar, os Estados Unidos (ANFALPET, 2012).

Tem-se produzido inúmeras ofertas criativas de produtos e serviços no segmento pet (SEBRAE, 2012). Um desses serviços tem sido a criação dos hotéis para animais domésticos, ou pet hotel. Alguns estabelecimentos já contam com acomodações individuais, oferta de canais por assinatura, com exibição de programas do canal Animal Planet, dentre outros. Tais detalhes visam minimizar o sofrimento dos pets durante o período de afastamento do dono.

Nos hotéis pet basicamente são oferecidos os serviços de hospedagem com quartos amplos, higiênicos, ambientes adaptados e específicos para esse fim, além de serviço de traslado, onde o animal é transportado de sua residência até o hotel e depois de volta para sua casa. Também nesses hotéis são oferecidos banhos para os animais, como serviço opcional, ou depois de certo número de dias no estabelecimento, dentre outros serviços que tornam a estada do animal segura e confortável (AFONSO et al., 2008).

Os hotéis para cães conservam a mesma prática de um hotel tradicional, onde se deve ligar para fazer reservas e escolher o tipo de aposento e serviços. Possuem espaços coletivos para brincadeiras, banho de sol e socialização, e unidades habitacionais normalmente individuais cobertas. Grande parte desses estabelecimentos tem algumas exigências como carteira de vacinação em dia, vermifugação (controle de vermes) atualizada, além de uma consulta ao veterinário (TUBALDINI, 2014). Ainda segundo o autor, existem os hotéis pet friendly, hotéis tradicionais que aceitam hospedar os animais de estimação junto com seus donos.

Assim como na hotelaria convencional, a hotelaria animal se mantém basicamente dos serviços, devendo se adequar às inovações que visam assegurar o conforto e a segurança dos hóspedes, garantindo novos clientes e fidelizando os já existentes. 
HOTELARIA PARA ANIMAIS DOMÉSTICOS: UM ESTUDO DE CASO SOBRE AS FERRAMENTAS E ESTRATÉGIAS DE MARKETING DE UM HOTEL PET EM FORTALEZA-CEARÁ

\section{METODOLOGIA}

Tratou-se de uma pesquisa de campo, de caráter exploratório, com abordagem qualitativa. A pesquisa qualitativa propicia uma observação mais detalhada da investigação, além de descrever a complexidade do comportamento humano preocupando-se em examinar e apreciar variáveis complexas (LAKATOS; MARCONI 2010).

O cenário da pesquisa foi um hotel pet, que vem se destacando nas redes sociais por seus serviços prestados no segmento em questão. $\mathrm{O}$ universo da pesquisa foi composto pelo gestor da empresa, com vasta experiência na área.

A coleta de dados foi realizada através de uma entrevista. A entrevista tem como objetivo obter informações importantes e através disso compreender as perspectivas e experiências das pessoas entrevistadas. Refere-se a uma conversação realizada entre duas pessoas, onde uma é o entrevistador e a outra o entrevistado (LAKATOS; MARCONI, 2010).

Foi utilizada a entrevista estruturada, com quatro perguntas abertas para que o entrevistado pudesse discorrer sobre o assunto. A entrevista estruturada contém uma sequência de perguntas fixas, cuja ordem e redação permanecem invariáveis para todos os respondentes (GIL, 1999). O instrumento da coleta de dados da pesquisa foi aplicado em março de 2015, considerando a disponibilidade do entrevistado. Ressaltando que o dia e o horário foram marcados com antecedência através de ligação telefônica.

Realizou-se uma breve explicação de como se daria a entrevista e de que a mesma seria gravada para posterior análise dos dados. Foi ressaltado que o conteúdo da gravação seria manipulado apenas pelo pesquisador. As falas do entrevistado foram transcritas na íntegra para a análise dos dados coletados. A fim de garantir o anonimato do participante, o mesmo foi identificado no estudo como Entrevistado X.

\section{RESULTADOS E DISCUSSÕES}

A primeira questão aplicada versou sobre as estratégias de marketing para atrair clientes. Como resultado, constatou-se que a empresa utiliza as redes sociais para promover a divulgação do estabelecimento com imagens dos espaços e serviços oferecidos, além de outras estratégias apresentadas na fala do entrevistado abaixo.

Nossos serviços são específicos para cães e divulgados através de site, contendo informações sobre o que oferecemos ao cliente, possuímos páginas nas redes sociais como facebook, instagram e twitter, mostrando através de fotos a acolhida e trata- mento aos animais. Divulgamos as fotos com a autorização do dono do animal e nossos clientes ficam felizes em ver as fotografias do seu cão em momentos de lazer e descontração. Realizamos também festas de aniversários para o cão, basta solicitar um orçamento do buffet e do espaço que garantimos a diversão do aniversariante e dos convidados. Trabalhamos com pacotes para feriados e alta estação, fazendo preços diferenciados para nossos clientes (ENTREVISTADO X, PESQUISA DIRETA, 2015).

$\mathrm{O}$ investimento em marketing está sendo feito por meio das mídias atuais, por darem um retorno em menor tempo e com um custo reduzido. Dentre esses recursos estão as redes sociais na internet, sites do próprio empreendimento, blogs, revistas especializadas, televisão e rádio, sendo que, estes dois últimos aparecem em menor proporção (ARAÚJO; COELHO, 2013).

Observa-se que a estratégia utilizada atende às necessidades da contemporaneidade, pois a sociedade está conectada à internet durante boa parte do dia. Divulgando seus serviços nas redes sociais, a empresa terá uma maior garantia de visibilidade.

A segunda questão abordou os serviços oferecidos no hotel pet e possíveis diferenciais no mercado, a fim de fidelizar o cliente. Como resultado verificou-se que o empreendimento investiu em conforto e segurança tanto para a estada dos animais como para um melhor desempenho das atividades laborais dos funcionários, como pode ser observado na fala a seguir.

\begin{abstract}
O ambiente comporta no máximo 25 cães, contando com recepção para o check-in do animal, deck para os donos do cão, sala de estética climatizada, jardim, espaço para recreação, piscina. Todos os apartamentos são climatizados e decorados para que o animal se sinta em casa. Para nos dar segurança, possuímos sensor de presença e somos monitorados por uma empresa de segurança. Para fidelizar o cliente, buscamos prestar nossos serviços com qualidade e eficiência. Evitar erros é essencial no mercado pet (ENTREVISTADO X, PESQUISA DIRETA, 2015).
\end{abstract}

O segmento de hotelaria para animais domésticos obteve um crescimento considerável nos últimos anos em razão de um maior número de pessoas passarem a criar pets. Em casos de viagem, necessitam deixar seus cães e/ou gatos em um local apropriado, onde possam ficar seguros e confortáveis (AFONSO et al., 2008).

Os hotéis pet têm investido em monitoramento com câmeras, como diferencial, além disso, proporcionam ambiente confortável, amplo, limpo, passeios diários com atividades recreativas, alimentação balanceada por profissional especializado, dentre outros (NETO, 2011). 
HOTELARIA PARA ANIMAIS DOMÉSTICOS: UM ESTUDO DE CASO SOBRE AS FERRAMENTAS E ESTRATÉGIAS DE MARKETING DE UM HOTEL PET EM FORTALEZA-CEARÁ

Percebe-se que, a inovação dos serviços oferecidos se faz necessário para desempenhar um diferencial competitivo dentro do mercado atuante e assim atrair novos clientes e manter os clientes mais antigos. $\mathrm{O}$ conforto e a infraestrutura oferecida também buscam a excelência, a fim de garantir a qualidade no serviço e possível fidelização do consumidor.

O terceiro questionamento buscou identificar as exigências do hotel pet para o procedimento de check-in do animal. Como resultado notou-se que é adotada uma série de precauções para uma estada segura do animal, como descrito na fala do entrevistado, a seguir.

\begin{abstract}
Os donos dos cães devem apresentar a carteira de vacinação completa e atualizada, vermifugação atualizada e controle mensal de pulgas e carrapatos do animal e preencher o termo de responsabilidade. Fêmeas no período do cio, cães agressivos e filhotes menores de quatro meses não ficam sob nossa responsabilidade no hotel no período de alta temporada, pois há uma grande quantidade de cães e apresentam ameaças aos mesmos, mas na baixa temporada quando temos um maior controle dos animais e o ambiente não está lotado eles são bemvindos. Não podemos nos responsabilizar por uma cadela que engravidou, filhotes são sensíveis e podem ter rejeição ao ambiente e os cães raivosos podem agredir outros hóspedes ou funcionário do nosso hotel pet (ENTREVISTADO X, PESQUISA DIRETA, 2015).
\end{abstract}

Check-in é o registro da entrada do hóspede no empreendimento hoteleiro. No hotel pet o procedimento é semelhante, faz-se uma coleta de dados sobre o animal e é necessária a apresentação da carteira de vacinação no ato do registro (PETROCCHI, 2007).

Ao mesmo tempo em que essa série de medidas adotadas no ato do check-in se mostra rígida, acaba por ser uma forma de estratégia, transmitindo para o cliente a certeza de que naquele local existe qualidade no serviço prestado e que seu animal de estimação estará seguro, pois para se hospedar é necessário cumprir todas as exigências. Uma empresa que prima por qualidade é aquela que busca ofertar produtos e/ou serviços que comtemplam os anseios dos consumidores ou os supera (KOTLER, 2000).

O quarto e último questionamento abordou a questão do preço e estratégias promocionais do estabelecimento. Como resultado constatou-se que o valor financeiro aplicado pela empresa varia de acordo com a raça, o porte do animal e suas necessidades e que as promoções são oferecidas através de descontos como é possível observar na fala abaixo.

O preço da hospedagem é realizado de acordo com o tamanho do cão e número de dias da estada em nosso estabelecimento. A cada 24 horas de estada é cobrada uma diária, mas para o check-out, damos uma margem de duas horas a mais para a retirada do animal. O tamanho está relacionado ao peso do cão, por exemplo, um cão pequeno tem de um a dez quilos. Os preços variam de 35 a 75 reais, dependendo do período do ano. Cães com necessidade de cuidados especiais terão um acréscimo de $20 \%$ na diária. Necessidades especiais são: cuidado com uma pata quebrada, deficiência visual, auditiva, motora e outras. Quanto às promoções, se o cliente chegar com dois cães, damos $10 \%$ de desconto na estada do segundo animal, se o cliente for hospedar mais de três cães, terá $15 \%$ de desconto na diária a partir do segundo cão (ENTREVISTADO X, PESQUISA DIRETA, 2015).

No que se refere aos serviços oferecidos, a média de preço da diária varia entre 35 e 65 reais, relativos à raça e ao porte do animal, além dos serviços opcionais, os quais os clientes optam ou não, no momento da contratação (ARAÚJO; COELHO, 2013).

Os consumidores de hoje estão mais atentos com relação aos valores cobrados por serviços recebidos, e tem como hábito fazer pesquisa de preço para avaliar onde estão as melhores opções. Cientes da existência desses consumidores, os empresários fazem uma pesquisa de mercado para analisar a concorrência, a fim de oferecer o melhor serviço, considerando os custos e os benefícios.

\section{CONSIDERAÇÕES FINAIS}

O estudo mostrou as estratégias de marketing utilizadas por um hotel pet de Fortaleza - Ceará. O empreendimento tem se adequado às exigências e tendências do mercado, principalmente no que se refere às tecnologias. O mercado capitalista, repleto de constantes inovações, requer que os prestadores de serviços e seus produtos estejam sempre atualizados de acordo com as necessidades do cliente.

O objetivo da pesquisa foi alcançado, uma vez que se constatou quais as principais ferramentas de marketing utilizadas pelo empreendimento para a divulgação e venda dos produtos e serviços, sendo elas o próprio serviço, o preço e a promoção. O valor financeiro cobrado pela estada varia de acordo com a raça, o porte do animal e suas necessidades, as promoções são oferecidas através de descontos e o serviço busca proporcionar conforto e segurança ao cliente.

O primeiro objetivo específico foi atingido, pois foi identificado que as estratégias de marketing para a divulgação e venda dos produtos e serviços do empreendimento estão baseadas nos meios de comunicação, 
HOTELARIA PARA ANIMAIS DOMÉSTICOS: UM ESTUDO DE CASO SOBRE AS FERRAMENTAS E ESTRATÉGIAS DE MARKETING DE UM HOTEL PET EM FORTALEZA-CEARÁ

em especial, as redes sociais, promovendo o estabelecimento com imagens dos espaços e serviços oferecidos. Neste quesito, os clientes ficam satisfeitos ao participarem de forma direta nessa publicidade, com a imagem de seus animais de estimação, no momento da estada.

Quanto ao segundo objetivo referente às exigências para a estada do animal, notou-se que várias precauções para uma permanência segura do pet devem ser atendidas, para evitar complicações futuras para o animal de estimação e seu dono, funcionários e responsável pelo empreendimento.

O terceiro e último objetivo específico foi atendido, pois os serviços oferecidos pelo hotel pet foram identificados. O empreendimento investiu em conforto e segurança tanto para a estadia dos animais como para o desempenho das atividades para os funcionários, há piscina, quartos climatizados, câmeras de segurança, área de recreação, dentre outros. Os diferenciais oferecidos, sem dúvidas, contribuem para a fidelização do cliente.

Através desse estudo, verificou-se que um empreendimento desse ramo requer profissionais com um mínimo de preparação para atender os clientes e dar os cuidados necessários aos animais e que o mercado exige qualidade nos serviços e constante adaptação às tecnologias que surgem no mercado pet e que as ferramentas de marketing contribuem para que a empresa atinja essas exigências.

Que este estudo seja incentivo para novas pesquisas na área de hotelaria para animais domésticos, uma vez que não há muitos estudos na área. Sugere-se como possíveis temas para futuras pesquisas: as novas tendências do mercado pet para a hotelaria; empreendedores de sucesso na hotelaria pet.

\section{REFERÊNCIAS}

AFONSO, T.; BERDASCO, L.; MEDEIROS, T.; REJOWSKI, M. Mercado pet em ascensão-hotelaria para cães e gatos em são paulo. Revista Brasileira de Pesquisa em Turismo, Associação Nacional de Pesquisa e Pós-Graduação em Turismo, v. 2, n. 4, p. 102-123, 2008.

ANFALPET. Pets que movimentam bilhões de reais. 2012. Disponível em: <http://www.petshopmagazine. com.br/tag/anfalpet/> Acesso em: 02 Fev 2015.

\section{ARAÚJO, J. N.; COELHO, S. D. Tendências e} investimentos em hotéis para cães em Fortaleza-CE sob a ótica dos empresários do segmento. Dissertação (Trabalho de Conclusão do Curso de Tecnologia em Hotelaria) - Instituto Federal de Educação, Ciência e Tecnologia do Ceará, Ceará, 2013.
BERNASCONI, M. Estrutura e gestão dos canais de distribuição na indústria de alimentos para cães e gatos (petfood). Dissertação (Mestrado) Universidade Federal de São Carlos, 2007.

BOONE, L.; KURTZ, D. Marketing contemporâneo. 8. ed. Rio de Janeiro: LTC, 1998.

BRASIL. Decreto $n^{0} \mathbf{4 0 . 4 0 0 ,}$ de 24 de outubro de 1995. 1995. Disponível em: <http://governo-sp.jusbrasil.com.br/legislacao/173542/ decreto-40400-95> Acesso em: 23 Fev 2015.

COBRA, M. Administração de Marketing. 2. ed. São Paulo: Atlas, 1992.

DIAS, S. R. Gestão de Marketing. São Paulo: Saraiva, 2006.

GIL, A. C. Métodos e técnicas de pesquisa social. 5 . ed. São Paulo: Atlas, 1999.

JACON, C. P. Contribuições para Compreensão dos Programas de Fidelidade de Clientes: uma pesquisa no setor de cartões de crédito. Dissertação (Dissertação de Mestrado Profissionalizante em Administração) - Programa de Pós-Graduação e Pesquisa em Administração e Economia, Faculdades IBMEC, Rio de Janeiro, 2005. Disponível em: <http://www.dominiopublico.gov.br/pesquisa/ DetalheObraForm.do?select_action=\&co_obra= 30470> Acesso em: 30 Mar 2018.

KOTLER, P. Administração de Marketing. 5. ed. São Paulo: Prentice-Hall do Brasil, 2000.

Marketing de A a Z. São Paulo: Editora Campus, 2003.

Administração de Marketing. 10. ed. São Paulo: Prentice Hall, 2004.

LAKATOS, E. V.; MARCONI, M. A. Metodologia

Científica. 5. ed. São Paulo: Atlas, 2010.

LAS CASAS, A. L. Marketing: conceitos, exercícios, casos. 8. ed. São Paulo: Atlas, 2009.

MADRUGA, R. Guia de implementação de marketing de relacionamento e CRM: o que e como todas as empresas brasileiras devem fazer para conquistar, reter e encantar seus clientes. 1 . ed. São Paulo: Atlas, 2004.

MIRANDA, F. Condomínios têm ambientes exclusivos para o seu pet. 2011. Disponível em: <http://www.turismo4patas.com.br/htms/novidade. 
asp?id_novidade=745/2011/04> Acesso em: 23 Fev 2015.

NETO, E. S. Plano de marketing para hotel de animais de estimação. 1 . ed. Rio Grande do Sul: UFRGS, 2011.

PETROCCHI, M. Hotelaria: planejamento e gestão. 2. ed. São Paulo: Pearson Prentice Hall, 2007.

QUADROS, M. C. R. M. Teoria, Prática e Ferramentas. 1. ed. Florianópolis: Visual Books, 2010.

SABATINO, L. Fidelização: a ferramenta de marketing que promove relacionamentos duradouros com o cliente. 1 . ed. Rio de Janeiro: Reichmann e Affonso Editores, 2003.

SEBRAE. Fique ligado às perspectivas para o segmento de Pet Shops no Brasil. 2012. Disponível em: <http://www.revistaveterinaria.com.br/2012/01/25/ fique-ligado-as-perspectivas-para-o-segmento-de-pet- 1 shops-no-brasil/> Acesso em: 02 Fev 2015.

SMITH, P. Linguagem Animal - Comunicação interespécies. 1. ed. São Paulo: Mercuryo, 2004.

TUBALDINI, R. Hotel para cães. 2014. Disponível em: <http://www.cachorrogato.com.br/cachorros/ hotel-para-caes/2014/08/10>. Acesso em: 22 Fev 2015. 